\title{
ATAXIA, ASAPHIA, AND APRAXIA IN SPEECH.
}

By E. W. SCRIPTURE, LONDON.

THE best available method of recording speech is that shown in Fig. 1. The patient speaks into a wide tube. The vibrations and puffs of air pass to a flexible membrane, the movements of which are enlarged and recorded by a light lever.

An inscription of ' $p a$ ' spoken by a normal voice is given in Fig. 2 A. The straight line at the start corresponds to the time in which the lips were closed for ' $p$ ' (the occlusion). As the lips open,

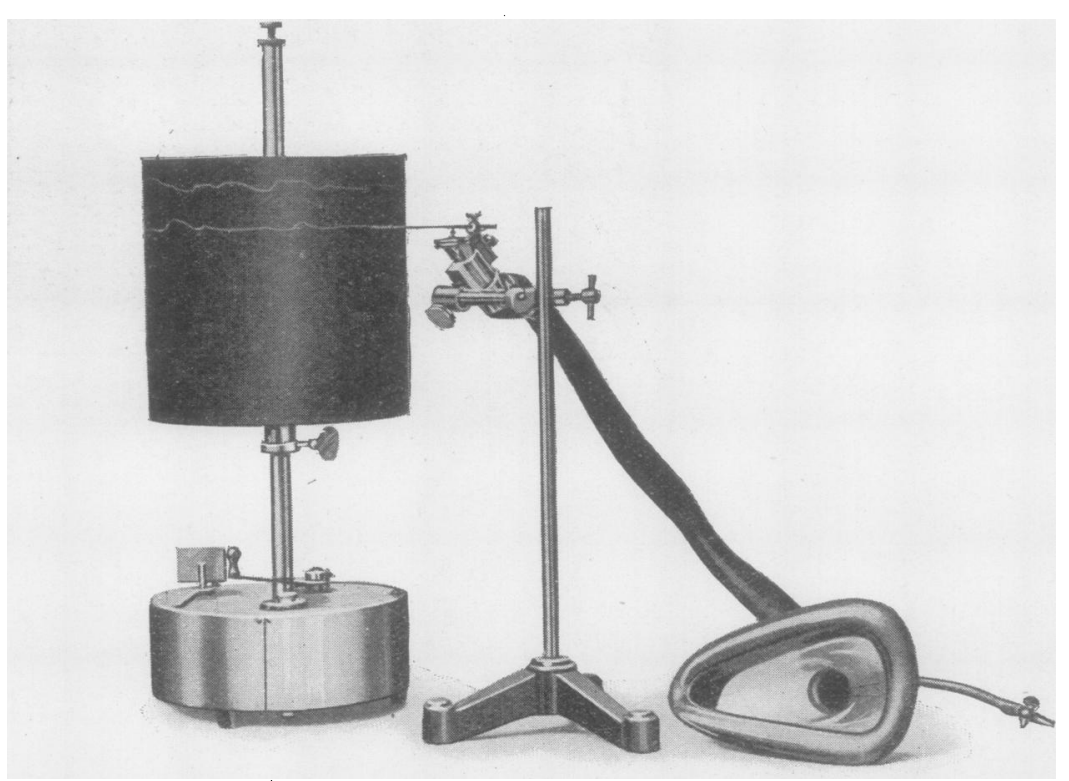

Fig. 1.-Apparatus for making Inscriptions of Speech.

The vibrations of air pass down the wide tube to a flexible membrane, and are recorded on smoked paper around a revolving drum.

a puff of air (the explosion) drives the line upward. This is followed by the vibrations of the vowel.

Even the simplest speech sound requires accurate co-ordination of the movements of many muscles. To make the sound ' $p$ ' the lips must be correctly closed by the muscles round the mouth. At the 
same time the velum must be raised to cut off the nasal passage. The muscles of breathing must produce the proper air-pressure behind the lips. At a certain moment the lips must open, before the velum drops or the breath pressure is rclaxed. These actions must be begun, continued, and ended at definite times and with definite degrees of force. The slightest error in the regulation will produce a modification of the sound. If the velum is not kept tightly closed for the whole of the time, the sound gets a nasal character (as in velar paralysis). If the pressure of the lips is not kept firm (as in muscular dystrophy), air issues between them and the sound is no longer occlusive (Fig. 2B). If the larynx vibrates during ' $p$ ' (as frequently in bulbar paralysis), the sound is like a ' $b$ ' (Fig. 2 c). If the time for ' $p$ ' is too long (as may occur in disseminated sclerosis), the sound becomes like that of a certain dialect (Fig. $2 \mathrm{D}$ ). If the breath pressure is relaxed before the lips are opened (as in some types of neurasthenia), there is no explosion and the sound is like that of a French ' $p$ ' (Fig. 2 E). The possibilities of disturbance are thus manifold even in a single syllable like 'pa'.

For the various muscles to be co-ordinated in a movement, the impulses to contraction that are sent to them from the nerve centres must be exactly in their right relative amounts

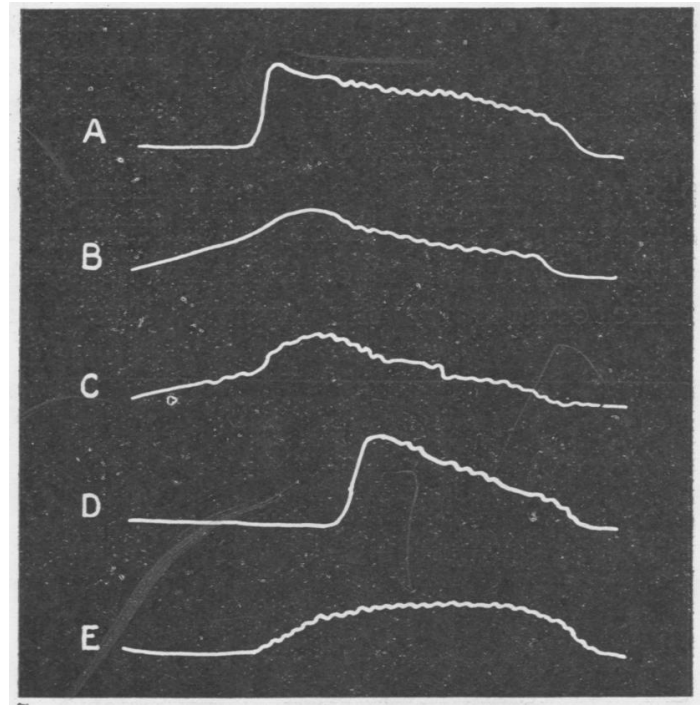

Fig. 2.-Inscriptions of 'PA'.

A. By a Normal Voice.-The inscription begins with a straight line corresponding to the closure of the lips (occlusion) for 'p'. The sudden rise of the line is due to the escape of air (explosion) as the lips are opened. The small waves register the vowel vibrations.

B. By a Case of Muscular Dystrophy.-The weakness of the lips hinders the complete closure for ' $p$ ', and the escaping air gradually raises the line. There is no explosion because there was no complete closure.

C. By a Case of Bulbar Paralysis.-The weakness of the lips hindered the complete closure. The larynx began quite improperly to vibrate during the ' $p$ '. The vibrations are irregular on account of the flabbiness of the vocal cords.

D. By a Case of Disseminated Sclerosis.-The lips were held tightly closed for a longer time than normally. The sudden irregularities in the vowel vibrations are a record of the fine intention tremor in the spanners of the vocal cords.

E. By a Neurasthenic.-The enunciation was thin and weak. The lack of the explosion for ' $p$ ' shows that the breath pressure was allowed to fall before the lips were opened. at each moment, and they must last for exactly the right times (innervation taxia).

If the impulses to the individual muscles are not properly 
co-ordinated, the resulting action is incorrect. The patient with disseminated sclerosis moves his finger in a jerky way when he tries to touch an object. He knows very well that his movement is not correct, but he is unable to adjust the nerve-impulses to the muscles correctly (innervation ataxia). The intention-tremor of the cricothyroid muscle in disseminated sclerosis causes jerks in the tension of the vocal cords. The vibration of the cords therefore becomes suddenly and briefly irregular from time to time. This is shown clearly in Figs. $2 \mathrm{D}$ and $3 \mathrm{~B}$. In none of the records of disseminated sclerosis I have made has this phenomenon been missing, although several cases showed no voice change that could be detected by the patient or by anyone else. In these cases, even after the record had shown the presence of the peculiarity, the ear could not perceive it. Siemerling asserts that in disseminated sclerosis there are minute lesions in all parts of the nervous system. This would include the taxic centres for the larynx. Every case of disseminated sclerosis

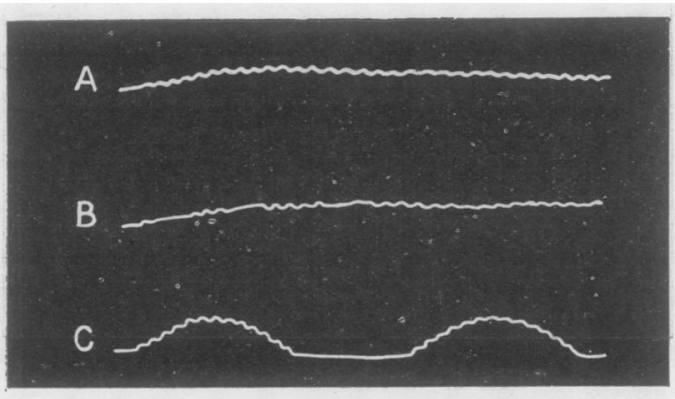

Fig. 3.-Inscriptions of 'AH', Sung.

A. By a Normal Voice.-The waves are quite regular. The line rises and remains at a constant height; this indicates a constant breath pressure.

B. By a Casc of Disseminated Sclerosis. - The vibrations show sudden jerks due to the intention tremor of the spanners of the vocal cords.

c. By another Case of Disseminated Sclerosis. -The waves come in groups separated by straight lines. This corresponds to the emission of the vowel as a series of short sounds separated by silences. would thus be expected to reveal itself in a speech inscription. ${ }^{1}$

In order to co-ordinate the impulses in time and force there must be sensations passing up from the muscles, so that their exact degrees of contraction at any moment can be used to regulate the impulses (sensory taxia). In tabes these sensations are lost. A tabetic patient could move his leg with accuracy if only his innervation taxic centres could know just. what the leg was doing at each instant; they do not know, and consequently the impulses are poorly adjusted (sensory ataxia). Although inscriptions have been made in over twenty cases of tabes, there was only one instance in which any abnormality of speech was found; this consisted in a momentary irregularity of the laryngeal vibrations like that in disseminated sclerosis.

The irregularities due to ataxia are opposed by an effort at control; the result of this effort may be termed 'anataxia'. The tabetic tries to keep his legs from flinging about (on account of sensory ataxia) by specially forced contractions (anataxia) that produce the 
familiar stamping gait. The patient with disseminated sclerosis feels his muscles jerking irregularly and makes efforts to control them. The extra efforts are so strong in some cases that, even in speaking, the patient will perspire profusely. The effects of anataxia from a case of disseminated sclerosis are illustrated in Fig. 3 c. Instead of a smooth sound as in Fig. $3 \mathrm{~A}$, the patient emits a series of short pieces of vowel separated by silences.

The individual muscles may be so well controlled that each sound would be considered to be made correctly if it were standing alone, and yet the complete sounds might vary abnormally from one another.

Fig. 4 shows the first portion of "Peter Piper's peppers" spoken by a paretic, in whose speech the ear could detect no abnormality whatever. Each ' $p$ ' shows a record of occlusion (straight line) and explosion (upward jerk). In normal speech the occlusions would be all nearly the same in length, and the explosions nearly the

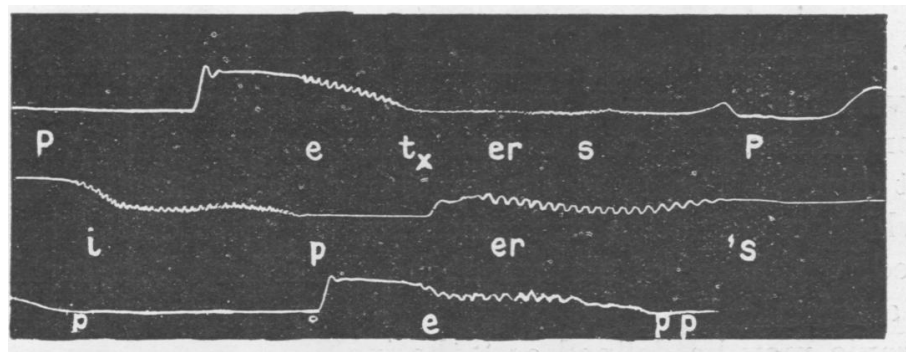

Fir. 4.-Portion of an Inscription by a Paretic.

The occlusions for the ' $p$ ' are not the same in length; the explosions differ in strength.

same in strength. Here some occlusions are longer, some shorter; some explosions are stronger, some weaker. The irregularity is in the entire form of the ' $p$ ', not in the action of the individual muscles used to make it. The irregularity is in the agreement in the type of sound to be regarded as a correct ' $p$ '.

The control of types of movement has been termed-not quite fortunately-_.'cortical taxia'. A paretic is said to show 'cortical ataxia'. As this control of types is really something quite different from the control of single muscles it needs a separate name; 'saphia' (Greek $\sigma a \phi \tilde{\omega} s$, precise) will be used here.

Just as a tabetic tries to overcome his ataxic gait by special efforts, so the paretic combats his unprecise movements (asaphia) by efforts at extra precision (anasaphia). A paretic will often remark that he can speak correctly as long as he can speak slowly. The slowness would thus be a part of his anasaphia. Many paretics speak with excessive care; their enunciation is like that of an over-precise 
orator. The uncertainty of enunciation is successfully combated by an extra effort at precision. It is often the case that a paretic will repeat a word correctly when he hears or sees it alone, but will do it incorrectly when he is off his guard by using it in a sentence. Both the slowness and the over-preciseness are phenomena of anasaphia. ${ }^{2}$

The speech of persons who have become hard of hearing often gradually changes. It loses more or less of its melodious intonation. It may become irregular in loudness. Various sounds may lose in their distinctness. Although the speech organs show no defects in their movements, they do not make quite the movements desired. What the speech organs actually accomplish is normally controlled mainly by hearing. When this guidance is lessened, the speaker may fall into lax and incorrect habits. This condition may be termed 'sensory asaphia', in contrast to the 'motor asaphia' of the paretic.

Just as the muscles are co-ordinated for simple movements, so complicated movements are grouped and co-ordinated for more general acts. This control of complex movements is termed 'praxia'. Taxia is the co-ordination of muscles in such a way that the movements are made correctly in a general way. Saphia is the co-ordination so that the movements are accurately adjusted to constant types. Praxia is the system of co-ordination that determines which combination and succession of parts of the body are to be moved, which line of movement is to be followed, and which object is to be attained. ${ }^{3}$

Apraxia may be defined as " the inability to perform movements or groups of movements intended to carry out a purpose, although all conditions of motility, sensation, and co-ordination may be preserved." "The practical distinction may be drawn that ataxia produces unprecise movements, while apraxia often produces the wrong ones; moreover, the movements in apraxia may not correspond to the purpose in hand, whereas they may correspond to some other purpose. The apraxic writes the wrong letter, but the letter itself may be correct."

Liepmann has reported a case with motor apraxia of the right arm, the left arm being normal. When told to put the right forefinger on the nose, the patient said 'Yes' and executed wide circling movements of his right hand in the air. When told to put the left forefinger on the nose, he did so correctly at once. When told to make a fist with his right hand, he made various absurd movements ; with the left hand the act was done properly at once. When Buck's patient was told to lift his right arm, he crossed it over the body, put his hand in his left axilla, and made various energetic but hopeless movements. "I understand perfectly well what you wish", said he, " but I do not succeed in doing it." 
In 'motor apraxia' the government of single movements or of simple groups of movements, such as blowing, whistling, speaking a single sound, etc., is disturbed. In saying "Peter Piper's peppers" the patient may get the words as a whole fairly correct, while making the sounds imperfect in a way not found in ataxia or asaphia; the larynx acts at the wrong times, the lips are closed too soon or too late, the tongue is moved in an incorrect way. The sounds are irregular and distorted. In Fig. 4 there are vibrations during ' $t$ ' of "Peter", whereas there should be none. The paretic has inserted a foreign element into the sound.

With 'transmission apraxia' a person attempting to speak a word may make every sound correctly but may get some of them in the wrong places. He may say "Peter's Piper's peppers", putting a correctly formed " $\mathrm{s}$ " at three places instead of two. He may know that he has spoken wrongly and may know just what sounds should be in the phrase, but any attempt to speak it produces transpositions and similar errors, because his ideas of the required movements go wrong in being transmitted into action.

The familiar experiment of repeating 'Troy boat' or a similar phrase very rapidly several times by normal persons results in such combinations as 'Troy boyt', 'Tro boat', etc. The person knows what he wants to say (ideational praxia intact); he makes all his sounds correctly (motor praxia intact); but in his hurry the wrong sounds are often used (transmission apraxia). Such phrases ('truly rural', etc.) are frequently used as a test of suspected alcoholism; the intoxication produces not only deformation of the sounds (ataxia) but also substitution as above (transmission apraxia).

In 'ideational apraxia' the person may have a general idea of' the action he wants to perform, but his notion of its parts and details is vague or impaired. A patient of Liepmann's received a cigar and a match-box. He opened the box, stuck the end of the cigar in it, and tried to shut the box-evidently carrying out the idea of cutting the end of the cigar instead of striking a match. Then he rubbed the end of the cigar on the side of the box as if lighting a match. A similar error in speech was that of a paretic who spoke of 'sweating fish' instead of 'swimming fish'.

The slowness and over-carefulness in the speech of some paretics must be attributed not only to anasaphia but also partly to anapraxia, that is, to an attempt to avoid the errors of apraxia. By special effort the patient who made the inscription in Fig. 4 could pronounce the phrase correctly.

The relations of the several kinds of centres may be summarized in the following way: The motor centres receive impulses and stimulate the muscles; the taxic centres control the action of the groups 
of muscles; the saphic centres send impulses to the taxic centres requiring movements that correspond to types; the praxic centres prescribe whole words, phrases, and expressions in speech.

On command to express a certain idea, the mind orders the praxic centre to speak the phrase "Peter Piper's peppers". Lower centres order that it shall be spoken as similar phrases have been spoken before. The saphic centres order that all the sounds shall conform to the typical sounds of English as they have been learned. The taxic centres select the muscles required for each sound, and look after their action.

\section{REFERENCES.}

1 "Records of Speech in Disseminated Sclerosis", Brain, 1916, xxxix, 455.

2 "Records of Speech in General Paralysis", Quart. Jour. Med., 1916, x, 118.

3 Liepmann, "Das Krankheitsbild der Apraxie", etc., Monats. f. Psychiat. u. Neurol., 1900, viii, 15, 102, 182. Wilson, "Contribution to the Study of Apraxia", Brain, 1908, xxx, 164. 